\section{DIREITO, RISCOEPERIGO:} ADECISÃOJURÍDICANA

\section{PERSPECTIVADASOCIEDADE} DORISCODEULRICHBECK

\section{LAW, RISK AND DANGER: THE JURIDICAL DECISION FROM THE PERSPECTIVE OF RISK SOCIETY FROM ULRICH BECK \\ DERECHO, RIESGO Y PELIGRO: LA DECISIÓN JURÍDICA EN LA PERSPECTIVA DE LA SOCIEDAD DEL RIESGO DE ULRICH BECK}

Como citar este artigo: SIMIONI, Rafael, FERREIRA, Mariana. Direito, risco e perigo: a decisão jurídica na perspectiva da sociedade do risco deUlrich Beck. Argumenta Journal Law, Jacarezinho-PR, Brasil, n. 30,2019, p. $109-130$.

Data da submissão: 22/11/2018

Data da aprovação: 02/05/2019

\title{
SUMÁRIO:
}

1. Introdução; 2. Sociedade industrial, pós-modernidade e sociedade do risco: a apropriação da riqueza e a distribuição dos riscos; 3. Risco, perigo e vulnerabilidade; 4. O Estado de Exceção e o princípio da reserva do possível na sociedade do risco; 5 . Conclusão; Referências.

\section{RESUMO:}

A sociedade contemporânea apresenta a característica de refletir sobre suas próprias condições de sobrevivência, em um processo de modernidade reflexiva. A questão do risco aparece como tema central, tendo em vista que permeia todas as decisões da sociedade e atinge as diversas classes e instituições. Ocorre que, em países de modernidade periférica, é possível constatar a existência de grupos sociais em situações de maior vulnerabilidade. É importante, portanto, considerar o Direito enquanto mecanismo de absorver e dividir os riscos. Pretende-se analisar o conceito de risco para Ulrich Beck estabelecendo uma relação entre modernização reflexiva e o risco na decisão jurídica.

1. Faculdade de Direito do Sul de Minas- Brasil 2. Universidade Federal de Minas Gerais- Brasil 


\section{ABSTRACT:}

Contemporary society has the characteristic of reflecting on its own conditions of survival in a process of reflective modernity. The issue of risk appears as central, since it permeates all decisions of society and affects the various classes and institutions. It happens that in countries of peripheral modernity, the existence of social groups in situations of vulnerability is notable. It is therefore important to consider law as a mechanism for absorbing and dividing risks. The intention, thus, would be to analyze the concept of risk for Ulrich Beck by establishing a relationship between reflexive modernization and risk in legal decision.

\section{RESUMEN:}

La sociedad contemporánea presenta la característica de reflexionar sobre sus propias condiciones de supervivencia, en un proceso de modernidad reflexiva. La cuestión del riesgo aparece como tema central, puesto que impregna todas las decisiones de la sociedad y alcanza a las diversas clases e instituciones. Ocurre que, en países de modernidad periférica, es posible constatar la existencia de grupos sociales en situaciones de vulnerabilidad. Asi, es importante considerar el derecho como mecanismo para absorber y dividir los riesgos. Se pretende analizar el concepto de riesgo para Ulrich Beck estableciendo una relación entre modernización reflexiva y el riesgo en la decisión jurídica.

\section{PALAVRAS-CHAVE:}

Direitos fundamentais; Modernidade reflexiva; Risco; Sociedade do risco; Vulnerabilidade.

\section{KEY WORDS:}

Fundamental Rights; Reflexive Modernity; Risk. Risk Society; Vulnerability.

\section{PALABRAS CLAVE:}

Derechos Fundamentales; Modernidad Reflexiva; Riesgo; Sociedad Del Riesgo; Vulnerabilidad. 


\section{INTRODUÇÃO}

A sociedade contemporânea atingiu um grau de industrialização que exigiu a sua reflexividade em termos de modernidade. Isso significa, para além de conceitos como pós modernidade, modernidade tardia ou ainda hipermodernidade, a sociedade contemporânea é uma sociedade moderna, mas que apresenta a característica de refletir sobre suas próprias condições de sobrevivência. Mais que planos ou estratégias orientadas para um futuro romântico e idealizado, a modernidade reflexiva exige um olhar para o presente, para aquilo que decidimos hoje.

Essa guinada reflexiva, que caracteriza a sociedade contemporânea, tem como uma categoria fundamental a questão do risco. Riscos e perigos, atualmente, fazem parte de todas as decisões da sociedade, atingem de modo ortogonal todas as instituições, grupos, classes que antigamente poderiam se encontrar isoladas em pequenos núcleos controlados de riscos. Os riscos ecológicos, por exemplo, não respeitam fronteiras políticas, tampouco de classe social. Riscos e perigos, portanto, fazem parte de qualquer experiência social.

Nesse cenário, torna-se importante refletir sobre o modo como o Direito desempenha uma função de absorção de riscos, ao lado da economia, da política e da ciência. Isso porque, o Direito instrumentaliza os modos de apropriação da riqueza e dos riscos, seja por meio da imputação jurídica, seja por meio da atribuição de responsabilidades.

O dever de indenizar os danos, contudo, parece ter sido desenvolvido em uma perspectiva onde risco e perigo eram tratados como externalidades, equiparados a casos fortuitos ou excludentes da responsabilidade. Entretanto, a sociedade contemporânea exige do Direito uma concepção de imputação mais abrangente, pois riscos e perigos não são apenas conceitos utilizados para justificar decisões equivocadas, mas são, sobretudo, realidades presentes em todas as dimensões da sociedade.

Todavia, ao mesmo tempo em que a modernidade apresenta uma tendência a equalizar a relação entre apropriação da riqueza e a submissão a riscos e perigos, em países de modernidade periférica, como o Brasil, ainda podem ser observadas situações de vulnerabilidade diferenciada. Naturalmente, riscos ecológicos de natureza global afetam tanto ricos quanto pobres, não fazendo nenhuma distinção de classe, de gênero ou de 
etnia. Em países de modernidade periférica, entretanto, é possível constatar a existência de grupos sociais que se encontram em situações de maior vulnerabilidade. Afinal, embora a riqueza não garanta segurança contra catástrofes ecológicas em países centrais, torna as populações mais vulneráveis a outros tipos de risco locais, como os riscos e perigos de doenças decorrentes de falta de saneamento básico, a submissão dos moradores de rua à violência, o subemprego de classes sem oportunidades de estudo.

Dessa forma, a questão central dessa pesquisa é refletir sobre o modo como o Direito, e em especial, a decisão jurídica, lida com essa questão dos riscos e perigos globais, ao mesmo tempo em que podem ser constatadas, também, situações especiais de vulnerabilidade. Nessa perspectiva, a pesquisa pretende analisar o conceito de risco na sociologia de Ulrich Beck estabelecendo uma relação entre os processos de modernização reflexiva e o risco na decisão jurídica.

Para tanto, a pesquisa explicita a concepção do autor de "sociedade do risco" como oposição a "sociedade industrial pós-moderna", bem como a relação entre risco, perigo e vulnerabilidade. A partir da constatação da problemática do risco como um problema universal e global, esse trabalho objetiva identificar os mecanismos contemporâneos de absorção do risco e o caso especial do "princípio da reserva do possível", como uma forma discursiva do Direito para justificar a negação da efetivação dos direitos fundamentais, típica de um Estado de exceção, tendo por base o argumento do risco.

Para que esses objetivos sejam alcançados, esta investigação utiliza o método analítico e a técnica de pesquisa bibliográfica, utilizando-se como marco teórico, a rede conceitual da sociologia de Ulrich Beck, em especial suas pesquisas a respeito do risco na sociedade contemporânea.

\section{SOCIEDADE INDUSTRIAL, PÓS-MODERNIDADE E SO-} CIEDADE DO RISCO: A APROPRIAÇÃO DA RIQUEZA E A DISTRIBUIÇÃO DOS RISCOS

Com o surgimento da sociedade moderna, os privilégios sociais gerados pelo nascimento deram lugar a uma sociedade em que os seres humanos podem ser classificados de acordo com sua atuação efetiva; com o papel desenvolvido na organização social, assim como por suas próprias decisões. Contudo, esse novo modelo de sociedade que deveria, a princí- 
pio, conferir mais liberdade aos indivíduos, é marcado por uma espécie de predestinação, um destino do qual ninguém pode escapar. (BECK, 1999, p. 77).

Essa sociedade é marcada pela certeza de que todos, independentemente da classe social, estão vulneráveis aos perigos, o que caracteriza a chamada "sociedade do risco". Nesse sentido, esclarece Beck que a sociedade do risco é, em suas últimas consequências, uma sociedade do risco global, na medida em que os riscos produzidos não possuem limites no tempo e no espaço. (BECK, 1999, p. 29). Ressalte-se que a citada ideia de predestinação aproxima-se mais da sociedade dos riscos do período Idade Média do que da sociedade de classes do século XIX.

Frise-se que dois fatores oportunizaram tal mudança de paradigma, ou seja, da sociedade de classes para a sociedade de riscos. O primeiro deles, os avanços em matéria de produção e tecnologia, bem como pelas políticas desenvolvidas pelo Estado social, o que tem o condão de diminuir a miséria material (BECK, 1998, p. 25). Por outro lado, tal processo de aumento da produtividade demanda que os riscos e perigos sejam permitidos, ainda que ainda não seja possível prever suas dimensões. Nesse sentido, leciona Beck:

Em primeiro lugar, essa mudança se consuma (como sabemos hoje), na medida em que o nível alcançado pelas forças produtivas humanas e tecnologicas, bem como pela segurança e regulação do Estado social foi possível reduzir objetivamente ou excluir a miséria material autêntica. Em segundo lugar, esta mudança categorial ao mesmo tempo que pelo aumento das forças produtivas no processo de modernização sejam liberados os riscos e os potenciais de autoameaça em proporções desconhecidas até o momento. (BECK, 1998, p. 25).

O ser humano desenvolveu técnicas para proteger-se das ameaças da natureza, como a construção de abrigos e a plantação de alimentos, sendo capaz de gerenciá-la para obter benefícios. Por outro lado, o homem está entregue às ameaças oriundas da parcela da natureza que foi absorvida pela indústria e que, por isso, foi contaminada.

$\mathrm{Na}$ sociedade moderna atual, a produção social da riqueza vem acompanhada pela produção de riscos. Nesse sentido, a questão da divisão de riquezas da sociedade pré-industrial é substituída pela questão da 
produção e da repartição dos riscos produzidos. Destaque-se que a sociedade do risco não perde de vista o capitalismo, mas com ele se coaduna, se elevando a um novo nível, transformando a modernização em um big business (BECK, 1998, p. 29).

A pergunta inicial, nesse contexto, deve ser: não teriam as ameaças e riscos diminuído progressivamente à medida em que os anos se passaram? "A redução da mortalidade infantil, os anos extras, o novo estado de bem estar e o enorme progresso tecnológico" (BECK, 1999,p. 75, tradução nossa) não seriam prova cabal da redução dos riscos produzidos?

Para chegar à resposta de tal questão é necessário ressaltar que os riscos atualmente produzidos são uma incerteza provocada, em relação às quais ninguém pode precisar quais as dimensões e consequências. Ademais, os riscos e seus desdobramentos não respeitam fronteiras geográficas, tampouco classes sociais, se alastrando por todo o Planeta.

Nesse sentido, "aos seres humanos está negada a certeza definitiva." (BECK, 1999, p. 77, tradução nossa). Todavia, seria correto permitir a ocorrência de tais riscos tão somente aceitando que eles fazem parte do progresso sem, contudo, fazer uma análise de quem deles se beneficia e de quem por eles é prejudicado?

Os riscos, assim como as riquezas são divididos. A diferença é que no caso das riquezas sociais, trata-se de bens de consumo, de oportunidades, de aquisição de recursos. Os riscos, por sua vez, são sempre divididos com o emprego de argumentação, visto que são um produto adicional e indesejado da industrialização e, por isso, devem ser suprimidos, ou no mínimo, reinterpretados.

Outra distinção entre riscos e riquezas é que enquanto estas têm uma dimensão palpável, aqueles têm uma dimensão irreal, isso é, não se restringem somente à consequências que já se consolidaram, mantendo, dessa forma, um componente futuro. O que quer dizer que os riscos se relacionam também a previsões a destruições iminentes. (BECK, 2000, p. 213).

Ademais, cite-se o fato de que, ao contrário da riqueza, os riscos não geram uma polarização. Não há uma rivalidade entre os que possuem e os que não possuem. No caso dos riscos, não há uma classe dos afetados que se opõe a uma classe dos não afetados. A classe dos afetados se contrapõe à classe dos que ainda não foram afetados, uma vez que os riscos têm efei- 
tos generalizados e universais, não respeitando fronteiras, nem limites de Estados nacionais (BECK, 2002, p. 29).

Em contrapartida, a distribuição de riquezas e a dos riscos têm em comum o fato de que ambos são repartidos de um modo específico entre as classes. A diferença está no fato de que as riquezas se acumulam nas camadas superiores, mais abastadas, o passo que os riscos se acumulam nas inferiores, já prejudicadas pela ausência de riquezas. Logo, essa dinâmica de divisão é responsável por fortalecer a sociedade de classes, aumentando as disparidades sociais. O risco de não conseguir um emprego, os riscos de dano e de intoxicação são exemplos de riscos gerados, respectivamente, pela falta de estudo e pela moradia em zonas residenciais baratas próximas a centros industriais, que são característicos das classes pobres (BECK, 1998, p.41).

A capacidade de enfrentar e de mitigar os riscos segue também a dinâmica social de divisão mencionada acima. Pessoas munidas de recursos financeiros podem comprar uma residência em um local afastado da contaminação industrial ou adquirir alimentos saudáveis, livres de contágio de agrotóxicos ou de metais pesados. É uma espécie de "fuga privada" das classes abastadas (BECK, 1998, p.42). Há de se ter em vista, contudo, que mesmo que as classes possam minimizar a exposição aos riscos, não estão isentas deles. Recursos com o ar e a água são recursos comuns, não havendo como escapar de seu consumo, anda que estejam poluídos.

$\mathrm{O}$ autor ressalta que as forças produtivas não devem ser confundidas com riquezas (BECK, 1998, p. 28). Aquelas causam danos estruturais irreversíveis, e podem ser aumentados, reduzidos ou minimizados de acordo com o que for socialmente definido. Por meio da possibilidade de tomar as referidas decisões de definições sociais é que as posições se transformam em posições políticas estratégicas.

Conforme foi dito, força de atração sistemática entre a pobreza extrema e os riscos extremos (BECK, 1998, p. 47; 1999, p. 81-82) é mais uma característica da sociedade dos riscos, que também pode ser relacionada à distribuição das riquezas. Nesse sentido, os países subdesenvolvidos se tornaram os principais receptores de "indústrias do risco", que nada mais é do que uma manobra de distribuição dos riscos. Graças a fatores como o número significativo de desempregados e de indivíduos de baixa escolaridade e salários, os chamados países de terceiro mundo apresentam 
uma maior receptividade para com as novas tecnologias trazidas por essas indústrias, as quais são vistas como uma oportunidade de geração de empregos e, por sua vez, de melhoria nas condições de vida.

Dessa forma, a fim de superar a miséria material, o que ainda não ocorreu efetivamente nos países subdesenvolvidos, tais países recebem indústrias altamente perigosas. Nas palavras de Ulrich Beck, à pobreza do Terceiro Mundo se adiciona o medo do desencadeamento das forças destrutivas da indústria do risco. E ainda, o demônio da fome é combatido com o belzebu da potencialização dos riscos. Em síntese, a sociedade atual ainda não é, totalmente, uma sociedade efetivamente do risco, possuindo também problemas típicos das sociedades com miséria material.

Todavia, diferentemente da pobreza, os prejuízos causados aos países subdesenvolvidos pelos riscos industriais podem estender-se ao resto do planeta. Ulrich Beck tece uma analogia com as enfermidades contagiosas dos pobres, que se alastravam pelas apertadas cidades medievais (BECK, 1998, p. 50).

Essa mudança na lógica da repartição, ou seja, a mudança do foco na divisão das riquezas para a dos riscos, pode ser associada a dois fatores. Primeiramente, ao fato de que o alto nível alcançado no âmbito das forças produtivas e tecnológicas permitiram reduzir a miséria material a que os indivíduos da sociedade pré-industrial estavam expostos, ainda que tal processo não esteja consolidado em todo o Planeta.

Em segundo lugar, esse crescimento vertiginoso dessas forças produtivas traz consigo riscos e um potencial de autoameaça cuja medida ainda não pode ser mensurada. Dessa forma, fica evidente que o processo de modernização, ou mais especificamente, de industrialização, torna-se, nas palavras de Beck, "reflexivo", sendo ao mesmo tempo, o tema e o problema. (BECK, GIDDENS, LASH, 1997, p. 16). Na sociedade do risco, o problema central é como minimizar, evitar, limitar e repartir os riscos e perigos produzidos no processo de industrialização, de modo que seus efeitos secundários não se tornem um obstáculo à continuidade do processo de modernização e nem ultrapassem o limite do suportável ecológica, médica, psicológica e socialmente. Destaque, entretanto, que em decorrência da reintepretação já mencionada, alguns riscos não são percebidos imediatamente pelo ser humano, sendo "invisíveis" (BECK, 1998, p. 33), o que se deve ao fato de os riscos serem apresentados como 
meras exposições de fatos, tais quais a constatação de que são encontradas altas concentrações de pesticidas no leite materno.

Para que o ser humano tome consciência da relação causa e efeito entre o processo de modernização e o risco, é necessário que fique evidente que a ameaça é um produto do modo de produção industrial. Com isso, no citado exemplo de Beck, é preciso que a mãe que reside em uma aldeia próxima de uma grande cidade e estabelece uma relação imediata entre a indústria química que produz pesticidas para plantas e as altas concentrações de agrotóxicos no leite. Outro aspecto que merece ser ressaltado é a importância da argumentação para legitimar a produção dos riscos, processo que antecede a repartição destes. Tece-se o discurso de que os riscos são um efeito secundário da modernização, seriam assim, um destino natural civilizatório, (BECK, 1998, p. 40) tendo sido gerados unicamente com a intenção benéfica de dar continuidade ao processo de modernização. Por este motivo, não seria possível que fossem refreados.

Com isso, as consequências danosas do processo de industrialização, que deveriam ser evitadas, são legitimadas pela ideia de que se ninguém produziu os riscos intencionalmente, não se pode atribuir culpa a um indivíduo específico. Os riscos seriam o preço a se pagar pela modernização, uma espécie de salvo conduto que admite que as consequências deveriam ser evitadas, mas, ao mesmo tempo, ignora a referida constatação e reparte os riscos de forma seletiva, criteriosa.

Deve-se ressaltar, entretanto, que os riscos não são uma inovação da Idade Moderna. O empreendimento marítimo de Cristovão Colombo para descobrir o novo mundo é citado pelo autor como um grande risco. A diferença, todavia, é que na sociedade pré-industrial os riscos eram pessoais. Na sociedade pós-industrial ou do risco, as situações de risco são globais, uma vez que questões como o armazenamento do lixo atômico representam uma possibilidade de destruição para todo o Planeta.

A fórmula "A miséria é hierárquica, o smog é democrático" (BECK, 1998, p. 42), o que significa que o smog não observa o princípio da causação atingindo, indistintamente, a todas as classes sociais, independentemente de quem o tenha produzido. A mencionada contaminação do ar, evidencia que ainda que as classes mais abastadas consigam minimizar os efeitos dos riscos, estes têm também um caráter igualador. Portanto, os riscos da modernização têm caráter universal, sendo seus efeitos nocivos 
incalculáveis e imprevisíveis.

A sociedade do risco não é uma sociedade meramente de classes, uma vez que a industrialização gera um "universalismo dos perigos" (BECK, 1998, p. 42) em que todos os habitantes do Planeta podem ser afetados por esses riscos, independentemente do local de sua produção. As cadeias alimentares, o ar e os recursos hídricos atravessam as fronteiras, o que evidencia os efeitos inespecíficos dos riscos. Nesse sentido, surge um "fatalismo ecológico" (BECK, 1998, p. 43) caracterizado pela onipresença dos riscos.

Ocorre que, nesse cenário, a natureza é posta na condição de vítima (BECK, 1998, p. 30), transformando uma discussão de cunho social em meramente natural. Por meio disso, os riscos e as consequências sociais ficam ocultadas por detrás do discurso da contaminação dos recursos naturais, desconsiderando que tal degradação é causada por uma estrutura social, por relações de dominância, por ideologias. A questão dos riscos é tida como de competência da natureza, da técnica, da economia e da medicina (BECK, 1998, p. 31), esquecendo-se de sua faceta social.

Seguindo essa lógica, a sociedade do risco apresenta um efeito bumerang, ou seja, há uma unidade entre culpado e vítima, visto que os riscos acabam afetando também quem os produz e/ou se beneficia deles. É um efeito circular do perigo. (BECK, 1998, p. 44). Dessa forma, fica explícita uma faceta dupla dos riscos. Estes afetam não só seu gerador de forma individual e direta (efeito bumerang), mas também afeta a todos os outros indivíduos (efeito igualador).

\section{RISCO, PERIGO E VULNERABILIDADE}

Uma distinção conceitual pertinente é a relação entre riscos, perigo e dano, na perspectiva de Ulrich Beck. O primeiro apresenta-se como um fenômeno cujas dimensões são incalculáveis, não sendo possível prever sua extensão. Nesse sentido, os riscos podem ser considerados invisíveis, uma vez que não sabendo a grandeza de suas consequências, não são percebidos imediatamente pelo ser humano. Por vezes, o risco pode vir a ser percebido somente quando seus efeitos se concretizam.

Os perigos, por outro lado, são aqueles cujas dimensões das consequências são calculáveis, previsíveis, sua extensão pode ser mensurada. São, portanto, ao contrário dos riscos, visíveis, a iminência do perigo é 
conhecida. Por fim, os danos são prejuízos já concretizados, calculáveis, assim como os perigos. Nessa perspectiva, não existe, portanto, a noção de dano futuro. Um dano futuro seria um conceito supérfluo, posto que seu significado já se encontra designado pelo conceito de perigo.

Cumpre tecer uma relação entre riscos e perigos. $\mathrm{O}$ aumento e ausência de mitigação dos riscos faz surgir situações sociais de perigo. Uma espécie de efeito bumerang (BECK, 1998, p. 29), conforme citado, que mais cedo ou mais tarde atingirá, além quem os produziu, isto é, quem deles tira proveito.

Há, entretanto, um aspecto, não explicitamente desenvolvido pelo pensamento de Beck, que precisa de atenção: a situação de vulnerabilidade de algumas classes, estratos ou comunidades, muito típicas de países de modernidade periférica, subdesenvolvidos ou simplesmente dos países de terceiro mundo, como é o caso do Brasil, o que significa que os riscos criam novas desigualdades entre os países. Embora as observações de Beck façam muito sentido para uma análise europeia da modernidade industrial e da reflexividade dessa modernidade no conceito de sociedade do risco, há situações diferentes em países que ainda não experimentaram essa modernidade.

Sem dúvidas, há riscos e perigos globais, como os ecológicos que afetam todas as classes e estratos sociais, não fazendo distinções de natureza econômica, política ou cultural. Todavia, há situações de risco em países periféricos como o Brasil, nos quais grupos sociais encontram-se em situações de maior vulnerabilidade a riscos e perigos do que ouros grupos.

Queremos refletir sobre a questão da vulnerabilidade, que abrange, de modo ortogonal, tanto o risco quanto o perigo. A revolução industrial não foi, de fato, tão revolucionária quanto diz seu nome. A autêntica revolução se deu no período pós-guerra, fase em que o desenvolvimento do setor de serviços possibilitou que as classes inferiores na hierarquia social tivessem oportunidades efetivas de ascensão. Em outras palavras, ocorreu uma melhoria das condições de vida das pessoas, sem que as desigualdades sociais tenham sido extintas. Originou-se um capitalismo sem classes, mas que ainda possui problemas sociais.

Nesse novo contexto, as desigualdades não são suprimidas, são meramente redefinidas em um processo de individualização dos riscos sociais. Dessa forma, as deficiências do sistema vigente são transformadas 
em fracassos pessoais, os problemas sociais são transformados em insuficiências pessoais, sentimento de culpa, medos do fracasso, conflitos internos e neuroses (BECK, 1998, p. 128).

A inovação do período pós-guerra deu origem a um processo de individualização. A sociedade moderna se desprendeu da ideia das grandes classes sociais e, em nome da própria sobrevivência material, as pessoas fizeram de si mesmas o centro de seus planos de vida. Dentro e fora da família, os indivíduos se convertem em atores da asseguração de sua existência no mercado. Os indivíduos se tornam dependentes do mercado de trabalho e da indústria e, assim, dependentes do consumo, das regulações sociais, entre outras possibilidades oferecidas pelo mercado (BECK, 1998, p. 98).

Ao longo desse processo, alguns grupos sociais como as mulheres e o proletariado, sofreram transformações que geraram a redução de sua condição de vulnerabilidade. No caso das mulheres, o ingresso no mercado de trabalho, uma vez que o dinheiro advindo dessa inserção tem poder material, poder simbólico e é capaz de alterar as relações de poder no casamento e na família. A feminização da educação (BECK, 1998, p. 107) possibilitou sua integração profissional, sendo um segundo fator para a redução da vulnerabilidade. Dessa forma, as mulheres que antes eram submissas a seus maridos e pais, por serem, em sua maioria, financeiramente incapazes, passaram a dividir o poder familiar.

O proletariado, por sua vez, teve sua vulnerabilidade reduzida pelo Estado de bem-estar social e pela luta por melhores condições de trabalho. A situação do desemprego, por outro lado, passa a ser visto como um "destino pessoal" (BECK, 1998, p. 117), algo devido às características do sujeito, reforçando a ideia de fracasso pessoal decorrente da individualização, o que pode ser tido como um aumento da vulnerabilidade para esse grupo.

Contudo, todos os grupos sociais estão afetados igualmente pelo desemprego, o que corrobora a noção de que não existem classes sociais na sociedade do risco.s. O aumento na vulnerabilidade se estende de uma maneira geral, para todos os indivíduos da sociedade. Frise-se que nao é possível desconsiderar que os mais afetados são os grupos já desfavorecidos, ou seja, os que já são vulneráveis, como as mulheres, mães trabalhadoras, pessoas sem formação profissional, doentes, idosos, estrangeiros e 
jovens (BECK, 1998, p. 119).

Os novos movimentos sociais são a expressão das novas situações de perigo e de risco advindas não mais da utilização da técnica industrial, mas do processo de individualização. Fatores como mais tempo livre, mais dinheiro, maior mobilidade, mais educação, quebram os nexos de vida, de classe e de família, (BECK, 1998, p. 108), rompendo o antigo paradigma social. Os novos riscos advêm da ruptura desse paradigma.

A mudança nas razões dos conflitos entre homens e mulheres são exemplo das transformações geradas pela referida quebra de paradigma. As divergências, atualmente, se devem às novas possibilidades de escolhas como a divisão do trabalho doméstico, as escolhas profissionais dos cônjuges, o cuidado dos filhos, decisões acerca da sexualidade. Nesse contexto, o matrimônio é um exemplo nítido de uma instituição que exige a divisão interna dos riscos (BECK, 1998, p. 154). As novas demandas a serem decididas, diferentes das demandas das gerações passadas, acarretam novos riscos. Nas situações em análise, percebe-se que a tomada de uma decisão pode gerar consequências arriscadas.

A questão é que ainda não se sabe o que ocorrerá quando se distorce a identidade das classes sociais e ao mesmo tempo se acentuam as desigualdades sociais. É impossível estabelecer ao certo se configura um final das classes ou o começo de uma nova configuração não tradicional (BECK, 1998, p. 123). É viável afirmar, entretanto, que a vulnerabilidade, atualmente, está associada não mais a classes sociais menos abastadas, e sim a pessoas que têm traços associados a desvantagens, tais quais a cor da pele, o sexo, a etnia a que pertence no caso dos imigrantes, a idade, as deficiências físicas. (BECK, 1998, p. 129)

Nesse contexto, cabe investigar os mecanismos de absorção dos riscos, dentre eles o Direito. Segundo Beck, a reflexividade da modernidade implica, dentre outras coisas, em uma consciência dos riscos e dos perigos aos quais todos nos encontramos submetidos (BECK, 1998, p. 18). Em que pese a percepção e da experiência de riscos e perigos globais, a sociedade segue produzindo suas decisões e realizando suas operações. Seguimos vivendo, apesar dos riscos e perigos. Isso acontece porque existem mecanismos sociais de absorção de riscos, que operam gerando confiança nas situações de decisão onde os riscos se fazem mais presentes. É o caso dos seguros, que estabelecem, mediante pagamento em dinheiro, a cober- 
tura de danos a bens submetidos a riscos ou perigos.

Giddens (1991, p. 83) e Luhmann (1992, p. 264) também já sinalizaram esses mecanismos sociais que funcionam absorvendo os riscos sociais, seja gerando confiança, seja confirmando as expectativas mesmo diante da contingência de frustrações. Conforme ensinamento de Luhmann (LUHMANN, 1992), o conceito de risco aparece de formas diversas em ramos cientificados variados, sendo relevante perceber os riscos e tentar minimizar ou absorver a quantidade de incerteza.

O risco torna-se assim uma categoria ambígua, pois ao mesmo tempo em que é uma ameaça ao funcionamento da sociedade, é um bom motivo para a economia continuar as suas operações na forma dos seguros contra riscos. Desse modo, a própria economia torna-se reflexiva, na medida em que transforma o risco da inadimplência que a paralisaria em mais uma oportunidade negócio, para a continuidade do processo econômico de modo reflexivo.

Os processos democráticos produzem também ambiguidade reflexiva. Os processos democráticos, que diluem a responsabilidade pelos efeitos colaterais das decisões, deslocando-a da instituição para todos os seus participantes. À medida em que a decisão política é atribuída a vontade de um povo ou mesmo à maioria dos participantes de um debate político, os riscos dos efeitos colaterais da decisão podem ser pulverizados dentre os participantes desse processo.

A passagem da sociedade industrial que apenas legitima os riscos para a sociedade dos riscos se dá pela autorreflexão, pela consciência do grau de ameaça que estes representam. Dessa forma, a mencionada sociedade dos riscos torna-se uma teoria política do conhecimento da modernidade, uma vez que representa a autocrítica (BECK, 1999, p. 127).

Os problemas que uma decisão política pode gerar, no futuro, tornam-se despersonalizados, diluídos na noção de povo e de vontade da maioria. Daí a noção de que a política da modernidade se preocupa mais com seus processos ou procedimentos de constituição legítima de decisões políticas do que, propriamente, de decisões políticas adequadas aos objetivos de uma nação.

Desse modo, a política transforma-se em reflexiva: mais do que os objetivos, metas ou finalidades anunciadas no Projeto Político de um Estado passa a debruçar-se, como uma das principais questões de sua agen- 
da política, com a segurança nos processos de participação democrática. Dentre outras coisas, isso garante uma descentralização da responsabilidade pelos riscos e perigos que poderão ser conhecidos ou experienciados no futuro.

Assim ocorre também com a ciência. O discurso científico é um paradoxal, visto que que garante tanto a certeza quanto a incerteza. A certeza a respeito das relações de causalidade do mundo e a incerteza a respeito das mesmas relações, já que o conhecimento científico, como já sinalizado por Popper (1994, p. 151), vive tanto de conjecturas quanto de refutações. É nesse processo circular de conjecturações e refutações, a verdade, a certeza e a segurança científicas só podem ser entendidas como provisórias, válidas até que outro conhecimento científico não as refutar.

Ademais, os riscos são preocupações comummente afetas às ciências físicas e engenharia (BECK, 1999, p. 77). Qual seria então o papel das ciências sociais na presente discussão?

E o Direito? Como se insere entre esses mecanismos sociais reflexivos de construção simbólica da segurança e de confiança? Independentemente do conceito de Direito que se possa ter em cada época e lugar - norma, leis, justiça, aeqvitas, prudentia, phronesis -, o fato é que desempenha uma importante função social de generalização simbólica de expectativas normativas, contra-fáticas (Luhmann, 2005, p. 188). Isso significaria que decidir-se de acordo com o Direito seria uma decisão pela segurança.

Entretanto, o Direito também se encontra marcado pela reflexividade típica da modernidade. As decisões jurídicas encontram-se igualmente submetidas a riscos e perigos, motivo pelo qual, muitas vezes, precisa recorrer aos valores que fazem parte de outros contextos sociais de decisão, tais como a certeza científica das perícias técnicas, as probabilidades das flutuações econômicas, a coerência da decisão jurídica com os princípios morais e valores éticos de uma determinada comunidade.

Isso implica no fato de que o próprio Direito, para tornar-se mais adequado às exigências sociais a que se encontra submetido, acaba por utilizar valores que fazem parte de outros contextos sociais decisórios, os quais são exatamente, os contextos que buscam no Direito - e não em outros lugares -, a certeza e a confiança.

As ciências naturais, portanto, não devem ser consideradas como autoridades vinculantes (BECK, 1999, p. 93), ante à política e o Direito. 
Atualmente, em um contexto em que a aplicação precede a discussão, ou seja, "é preciso criar bebês de proveta, criaturas artificiais geneticamente modificadas e construir reatores para esudar suas propriedades e caracteristicas de segurança”. (BECK, 1999, p. 95, tradução nossa), o debate sobre a extensão dos riscos se queda restrito aos cientistas. Logo, "A própria ciência aboliu o limite entre laboratório e a sociedade." (BECK, 1999, p. 95, tradução nossa).

\section{O ESTADO DE EXCEÇÃO E O PRINCÍPIO DA RESERVA DO POSSÍVEL NA SOCIEDADE DO RISCO}

A vivência dos riscos implica em um contexto de segurança perdida, o que dá origem a novas indagações, sendo a principal delas o como se quer viver? (BECK, 1998, p. 34), onde fica a tênue fronteira entre o dano razoável e o não razoável? O preço de uma catástrofe ecológica é inferior ao do desenvolvimento econômico?

Para responder a essas perguntas é necessário o diálogo entre a racionalidade social e a científica. Nas palavras do autor, "sem racionalidade social, a racionalidade científica está vazia e sem racionalidade científica, a racionalidade social é cega." (BECK, 1998, p. 36, tradução nossa).

Assim, pode-se distinguir duas fases claras e diversas entre si. A primeira delas a da sociedade industrial, fase esta que intensifica e legitima os riscos oriundos da produção industrial, tratando-os como riscos residuais. (BECK, 1999, p. 113).

Já a segunda fase, permeada por reflexividade, é denominada propriamente de sociedade do risco, fortemente marcada pela reflexão e oposição a aceitação dos referidos riscos residuais. Nessa estapa, busca-se investigar e explicar como os riscos podem ser melhor distribuídos. Em outras palavras, as consequências incalculáveis dos perigos produzidos pelos avanços tecnológicos são reconhecidas sob uma ótica de fundamentos do cenário social, bem como uma revisão das convenções e princípios predominantes da racionalidade. Desse modo, na sociedade do risco, esta se torna um tema e um problema. (BECK, 1999, p. 122).

Nesse contexto, cabe discorrer acerca do princípio da reserva do possível, segundo o qual a possibilidade e a extensão da atuação do Estado, no que tange à efetivação de direitos sociais e fundamentais, estão condicionadas à disponibilidade de recursos públicos. Desse modo, os 
direitos previstos em lei só podem ser concretizados caso haja recursos financeiros disponíveis.

Por outro lado, o Estado deve assegurar a concretização do mínimo existencial, ou seja, o direito inerente a todo ser humano de acessar o conjunto de prestações materiais necessários à garantia de uma existência digna. É facil observar que a insuficiência de recursos financeiros do Estado opõe-se, veementemente, à consolidação do mínimo existencial.

Deve-se ter em mente que a negação da efetivação de um direito com base somente no princípio da reserva do possível deve ser analisada com receio. É necessário que se demonstre, por meio de uma ponderação, que a opção pelo cumprimento efetivo do direito causará mais prejuízos do que vantagens.

No caso da sociedade do risco, os riscos industriais não são extintos ou sequer minimizados com fundamento na afirmação de que não há recursos financeiros suficientes para fazê-lo. Os tratamentos de resíduos como a fumaça proveniente dos automóveis e fabricas são muito onerosos, o que faz com que a esses detritos altamente poluentes não sejam desferidos o tratamento necessário para que não se tornem um risco à saúde do Planeta.

Na modernidade pós-industrial, os riscos são tidos como resultado do modo de produção, não sendo atribuídos especificamente a alguém. Desse modo, nas palavras de Ulrich Beck, a responsabilidade, quando atribuída a um indivíduo, é imputada ao membro mais fraco da cadeia produtiva sistêmica:

A agricultura contamina o solo ou são os agricultores, o elo mais frágil da cadeira dos ciclos de dano? Seriam talvez somente os mercados de consumo subordinados à indústria química de agricultura e de fertilizantes? Deveria ser feita uma desintoxicação preventiva do solo? As autoridades poderiam ter proibido a venda de agrotóxicos ou ao menos tê-la limitado drasticamente há muito tempo, mas não o fazem. Pelo contrário, com a aprovação da ciência, expedem mais permissões para a produção de agrotóxicos "não perigosos" que afetam a todos. A culpa seria das autoridades, da ciência e da política? Mas afinal eles não cultivam os campos. A culpa seria, pois, dos camponeses? Todavia, a estes têm sido atribuídas pela União Europeia a função de superproduzir em excesso para sobreviver economicamente. (BECK, 1998, p 38). 
Com a sociedade do risco, fica evidente o surgimento de novos conflitos sociais. Tal negligência quanto à efetivação dos direitos a ter os riscos industriais minimizados e o apego ao princípio da reserva do possível legitimam um Estado de exceção, uma vez que, se a produção dos riscos não é combatida ou sequer reduzida, faz-se necessário um mecanismo que permita dar um destino mais rápido aos produtos secundários da indústria. Seguindo essa lógica, o Estado de exceção, caracterizado pela suspensão temporária de garantias constitucionais dos indivíduos em situações de emergência nacional, seria um mecanismo conveniente, haja vista que possibilita a agilização da tomada de decisões visando, pretensamente, à proteção do Estado em casos de urgência.

Logo, a sociedade do risco traz uma urgência constante, uma predestinação, a certeza de que mais cedo ou mais tarde todos serão afetados pelos riscos da modernização. Tendo em vista que na sociedade do risco, a normalidade - a ausência da iminência de riscos não é uma prioridade - o Estado de exceção assume um caráter vitalício, destinando-se sempre a controlar as dimensões dos prejuízos causados pelos produtos secundários da industrialização, bem como a distribuí-los.

Dessa forma, tem-se um Estado de exceção ilimitado, que não atenta para os princípios da necessidade e da temporariedade. O Estado de exceção, que deveria ser aplicado em limites estritamente necessários ao reestabelecimento da normalidade, tendo por objetivo preservar, manter e defender o Estado Democrático de Direito, passa a ter efeitos que perduram enquanto houver a iminência de catástrofes decorrentes dos riscos da industrialização, sem prazo final.

Nesse diapasão, José Afonso da Silva, ressalta que:

sem que se verifique a necessidade, o estado de exceção configurará puro golpe de Estado, simples arbítrio; sem atenção ao princípio da temporariedade, sem que se fixe tempo limitado para vigência da legalidade extraordinária, o estado de exceção não passará de ditadura.(SILVA, 2000, p. 740)

Nesse diapasão, o caráter de excepcionalidade e temporariedade do Estado de exceção está desvirtuado, tendo se transformado em uma técnica de governo, segundo Giorgio Agamben, (2003, p. 13) em um "patamar de indeterminação entre a democracia e o absolutismo", a regra e não a exceção. 
Ainda nas palavras de Agamben:

O estado de exceção é [...] um espaço vazio de direito, uma zona de anomia em que todas as determinações jurídicas estão desativadas" e "O estado de necessidade não é um "estado do direito”, mas um espaço sem direito. (AGAMBEN. 2003, p. 79).

Os riscos tornam-se um pretexto para legitimar o Estado de exceção. A catastrófica sociedade do risco traria a necessidade de tomadas de decisões menos burocráticas, mais ágeis, mesmo que não houvesse a aprovação da pluralidade de agentes requerida no Estado Democrático de Direito. O desinteresse em combater os produtos secundários da modernização pode representar um pretexto para que seja necessário que o Estado de exceção se transforme em estado de normalidade, conferindo maior liberdade ao governo.

Logo, o estado de exceção, que permite que os direitos sejam efetivados no limite da reserva do possível, compromete a garantia do mínimo existencial, reduzindo-o, por vezes, meramente ao mínimo vital, o que não pode ser legitimado pela continuidade do desenvolvimento industrial. Ao Estado, cabe a proteção da sociedade, preservando a integridade e assegurando a máxima expressão de seus direitos fundamentais, e não os suspender. A citada proteção deve estar acima de qualquer pretensa necessidade de modernização.

Todavia, quando a sociedade compreende o mecanismo atual de repartição dos riscos e os questiona, incorporando tal questionamento à consciência de toda a sociedade, esta se mobiliza. Os riscos, antes vistos como funcionais e racionais, se transformam em ameaças a vida de toda uma sociedade, em verdadeiras disfuncionalidades e irracionalidades (BECK, 1999, p. 126).

Ocorre que mesmo quando os riscos são identificados, o que é combatido são seus sintomas, nunca suas verdadeiras causas (BECK, 1999p. 135). Isso porque o avanço científico e, consequentemente, o econômico, são vistos como positivos e desse modo, deseja-se a sua expansão no maior grau possível.

Cabe mencionar, entretanto, que os sistemas sociais são maleáveis e sua existência depende da tomada de decisões e da legitimação que se dá a eles (BECK, 1999,p. 144). Desse modo, segundo a teoria e Ulrich Beck, estão sendo criadas oportunidades alternativas de negócio que podem 
conduzir a uma mudança de paradigma na sociedade do risco, vejamos:

Minha tese é que em todos os campos de atividade - tecnologia, medicina, direito, organização do trabalho - está sendo criadas oportunidades para ações alternattivas diante da pressão das mudanças nos desafios e nas convicções fundamentais. (...) Tão logo algumas organizações empreendam o que pode ser chamado de "modernização ecológica" se fazem possíveis linhas alternativas de ação. Quando essas alternativas se tornam profissionais e rentáveis, dividindo profissões, fundando carreiras e abrindo mercados, possivelmente incluindo a escala global e dividindo, desse modo, o bloqueio de poder da economia, permitem e inclusive exigem novos tipos de conflitos e coalizões entre e dentro das instituições, partidos, grupos de interesses e público de todos os tipos e quando essa imagem da distante autorreferencialidade dos sistemas sociais ocorre estes são derrubados. (BECK, 1999, p. 144, tradução nossa).

Assim, torna-se essencial reconhecer que com as mudanças emergentes nos sistemas sociais nas formas de produção, possuem o condão de alteras a forma de produção e de legitimação dos riscos de produção. Desse modo, abre-se a possibilidade para que os direitos fundamentais não sejam protegidos e mais, efetivados, apenas na medida do possível, mas que sejam plenamente observados e garantidos em toda sua extensão.

\section{CONCLUSÃO}

Como resultados parciais, a pesquisa identificou a necessidade de se diferenciar com precisão os conceitos de risco, perigo e vulnerabilidade, uma vez que nos países de modernidade central, a percepção e a submissão aos riscos e perigos pode ser mais homogênea entre as diversas classes, comunidades ou etnias. Nos países de modernidade periférica, entretanto, como é o caso do Brasil, os riscos e perigos não constituem uma categoria universal: existem aqui, grupos sociais com diferentes índices de vulnerabilidade a riscos e perigos.

Além disso, verifica-se que a passagem da sociedade industrial para a sociedade do risco é permeada pela reflexibilidade, ou seja, a capacidade de refletir sobre as causas e as consequências dos ricos produzidos como resultado do processo de produção. Cabe ressaltar que tais riscos possuem o condão de afetar a toda a sociedade global em um verdadeiro efeito bu- 
merang, no qual os beneficiados pelos riscos também são, ainda que em proporção menor, prejudicados por eles.

O grande benefício de parcela da sociedade em razão do desenvolvimento industrial faz com que este seja visto como forma de solução dos problemas econômicos, o que faz com que as causas, do desequilíbrio ecológico e social, ainda que sejam conhecidas, não sejam combatidas, tampouco mitigadas. Nesse contexto, apenas os sintomas são reconhecidos.

Por outro lado, o fenômeno da produção e expansão dos riscos globais deve ser visto como um problema social, o que implica em considerar que a vítima são todos os membros da sociedade e não apenas o meio ambiente. Assim, cumpre identificar os riscos industriais como autodestrutivos, de modo que sua eliminação ou mitigação deveria ser alvo de todas os processos decisionais que permeiam a sociedade.

Importante observar que alternativas têm sido criadas e implementadas e que, a partir do momento em que esses novos modelos de produtividade tornam-se profissionais e rentáveis, estão aptos a substituir ao menos em parte os negócios com base na alta produção de riscos. Por meio dessa transformação na forma de pensar a produtividade, novos métodos que propiciem maior segurança à sociedade.

Isso demonstra a importância de se conceber os direitos fundamentais como mecanismos de enfrentamento dos riscos, refletindo, criticamente, sobre as atuais concepções de princípios, que estabelecem que estes são objetivos a serem efetivados apenas na medida do possível. Tal reflexão torna-se essencial, na medida em que nessas perspectivas, torna-se fácil utilizar o discurso do risco como uma justificativa para o não cumprimento de direitos fundamentais, em especial em relação aos grupos de maior vulnerabilidade.

Desse modo, embora o risco seja um argumento forte para justificar um Estado de exceção permanente em detrimento da garantia dos direitos fundamentais, não pode encontrar no Direito um mecanismo de absorção ideológica da sua problemática. O risco é uma categoria importante e presente em todas as decisões, mas não pode justificar, por si só, que a aplicação dos direitos fundamentais fique, no caso concreto, reservada ao possível.

\section{REFERÊNCIAS}


ADAM, Barbara; BECK, Ulrich; VAN LOON, Joost. The Risk Society and Beyond: Critical Issues for Social Theory. London, Thousand Oaks; New Delhi, Sage, 2000.

AGAMBEN, Giorgio. Estado de exceção. Tradução de: Iraci D. Poleti. São Paulo, Boitempo Editorial, 2003.

BECK, Ulrich; GIDDENS, Anthony; LASH, Scott. Modernização reflexiva: política, tradição e estética na ordem social moderna. Tradução de Magda Lopes. São Paulo: Unesp, 1997.

BECK, Ulrich. La sociedad del riesgo: Hacia uma nova modernidad. Tradução de: Jorge Navarro, Daniel Jimenéz e Maria Rosa Borráz. Barcelona; Buenos Aires; Ciudad del Mexico: Paidós, 1998.

BECK, Ulrich. O que é a globalização - equívocos do globalismo: respostas à globalização. Tradução de: André Carone. São Paulo, Paz e Terra, 1999.

BECK, Ulrich. La sociedad del riesgo global. Tradução de: Jesús Alborés Rey. Espanha, Siglo Veitiuno, 2002.

GIDDENS, Anthony. As consequências da modernidade. Tradução de: Raul Fiker. São Paulo, Editora Unesp, 1991.

LUHMANN, Niklas. Sociología del Riesgo. Tradução de: Silvia Pappe, Brunhilde Erker, Luis Felipe Segura. 1992.

LUHMANN, Niklas. El derecho de la sociedad. $2^{\text {a }}$ ed. Trad. Javier Torres Nafarrate, Brunhilde Erker, Silvia Pappe e Luis Flipe Segura. Ciudad de México: Herder; Universidad Iberoamericana, 2005.

POPPER, Karl Raimund. Conjeturas y refutaciones: el desarrollo del conocimiento científico. Trad. Néstor Miguez. Barcelona, Paidós, 1994. SILVA, José Afonso da. Curso de Direito Constitucional Positivo. 18 ${ }^{\mathrm{a}} \mathrm{ed}$. São Paulo: Malheiros, 2000. 